\title{
In vivo multi-modality tracking of the regenerative effects of the human induced pluripotent stem cell-derived cardiomyocytes (iCMs)
}

\author{
Morteza Mahmoudi, Eric Rulifson, Atsushi Tachibana, Mouer Wang, Joseph C Wu, Phillip Yang \\ From 18th Annual SCMR Scientific Sessions \\ Nice, France. 4-7 February 2015
}

\section{Background}

In vivo multi-modality cellular and molecular imaging of the engrafted iCMs is necessary to characterize the engraftment and the regional effects on the viability of the injured myocardium. Zinc finger nuclease (ZFN)mediated integration of the reporter gene into the AAVS1 locus in the iCMs and manganese enhanced MRI (MEMRI) should allow precise in vivo detection of myocardial regeneration.

\section{Methods}

In order to have multi-modal in vivo imaging of the stem cells, ZFN technology was employed to integrate a triple fusion RG (firefly luciferase (BLI), red fluorescent protein (RFP), and herpes simplex virus thymidine kinase (PET)) into the AAVS1 locus of iPSCs. iPSCs monoclonal lines were then differentiated into iCMs, under chemically defined conditions using CHIR $(4 \mu \mathrm{M})$ and C59 $(2 \mu \mathrm{M})$ small molecules to modulate the Wnt pathway activity. The produced iCMs were then fully characterized and injected into mice and tracked with several techniques.

\section{Results}

Co-localization of cardiac phenotype and striated morphology, flow cytometry measurement of $93 \%$ cardiac troponin (cTNT) associated with 75\% VCAM and 49\% CIRPA cell surface markers, the atomic force measurement with calcium flux were observed, which confirmed normal function of the iCMs (Fig. 1A). The iCMs were, then, transplanted into murine myocardial injury model. Two and four weeks post-injury, left ventricular ejection fraction (LVEF) was better preserved in the iCM-treated vs. PBS-treated mice (week 2: $33.1 \pm 4.4 \%$ vs. $26.1 \pm 7.9 \%$, $\mathrm{p}<0.05$ and at week $4: 35.1 \pm 8.4 \%$ vs. $16.1 \pm 0.2 \%, \mathrm{p}<0.05$ ). MEMRI also demonstrated increased \% myocardial viability by iCMs at week 2 measured $67.3 \pm 13.1 \%$, which decreased slightly by $-2.3 \pm 0.3 \%$ at week 4 while PBS treated cases conferred significant decrease $-17.4 \%$ at week $4(\mathrm{p}<0.05)$. Finally, the mean BLI signal, indicating iCM engraftment, demonstrated on days $14(\mathrm{n}=3)$ is 2.1 $\pm 0.6 \times 10^{3} \mathrm{p} / \mathrm{s} / \mathrm{cm}^{2 /} \mathrm{sr}$ and days $28(\mathrm{n}=3)$ is $4.2 \pm 2.2 \times 10^{3} \mathrm{p} /$ $\mathrm{s} / \mathrm{cm}^{2 /}$ sr. Robust in vivo expression of ZFN-edited BLI signal of iCM engraftment and sustained MEMRI signal of myocardial viability over 4-week duration demonstrated regeneration of the injured myocardium (Figs. $1 \mathrm{~B}$ and $1 \mathrm{C})$.

\section{Conclusions}

This study demonstrates the successful use of in vivo multi-modality imaging to confirm the regeneration of the injured myocardium. ZFN technology enables targeted site-specific insertion of RGs and MEMRI allows direct evaluation of myocardial viability. These imaging capabilities will allow clinical translation of iCMs.

\section{Funding}

NIH/NHLBI UM1 (HL-12-026). 


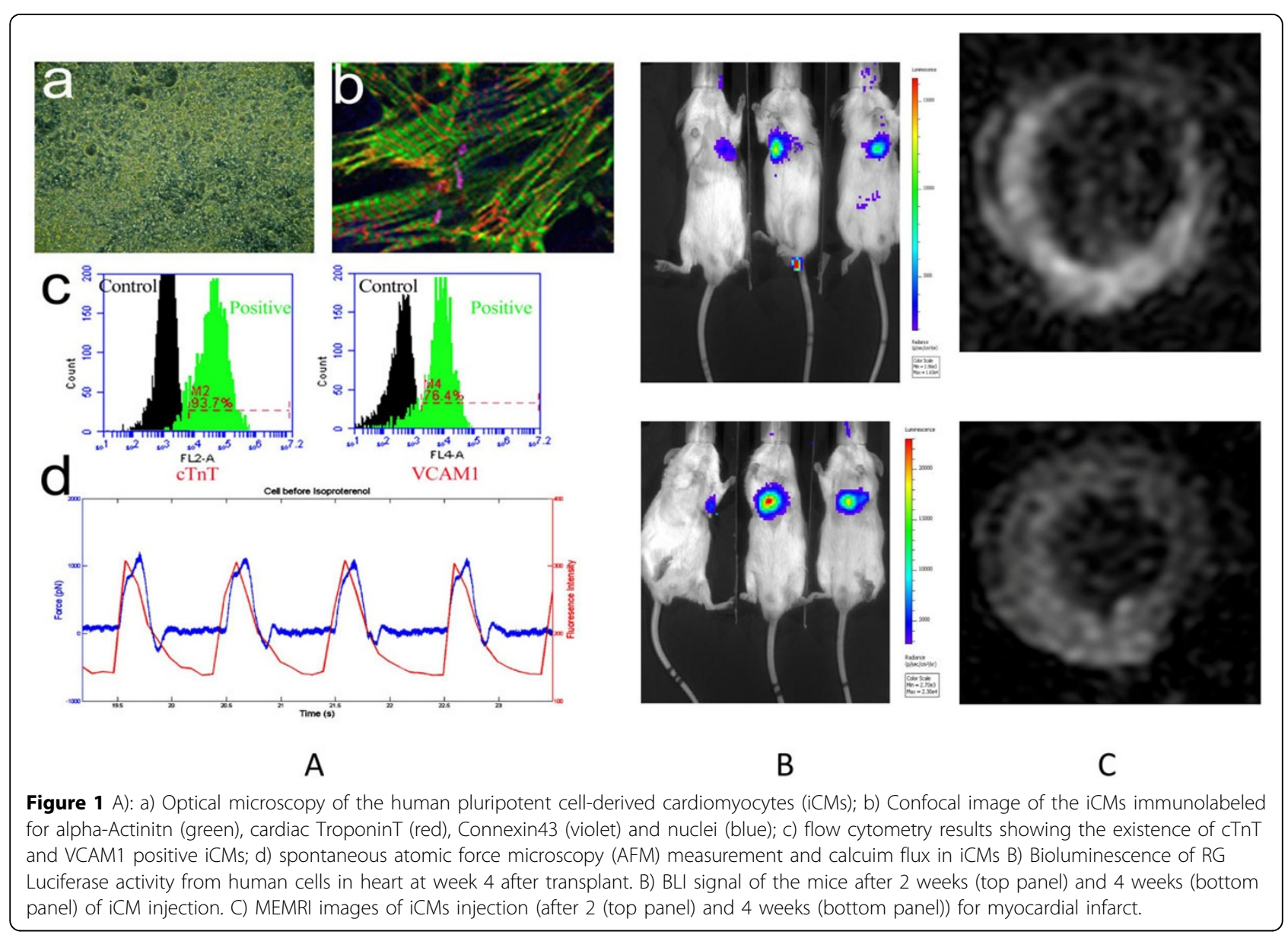

Published: 3 February 2015

doi:10.1186/1532-429X-17-S1-0119

Cite this article as: Mahmoudi et al: In vivo multi-modality tracking of the regenerative effects of the human induced pluripotent stem cell-derived cardiomyocytes (iCMs). Journal of Cardiovascular Magnetic Resonance 2015 17(Suppl 1):Q119.

\section{Submit your next manuscript to BioMed Central} and take full advantage of:

- Convenient online submission

- Thorough peer review

- No space constraints or color figure charges

- Immediate publication on acceptance

- Inclusion in PubMed, CAS, Scopus and Google Scholar

- Research which is freely available for redistribution 